\title{
Ganaya:
}

Gurnal I lmu Sasial dan \#umaniona Jayapangus Press

http://jayapanguspress.penerbit.org/index.php/ganaya Vol. 3 No. $1(2020)$

\section{Peran Komunikasi Hindu Terhadap Perilaku Pemuda Yang Ajeg Bali di Tengah Pusaran Globalisasi}

\section{Oleh:}

\author{
Bagus Ade Tegar Prabawa ${ }^{1}$, Ni Komang Sutriyanti \\ ${ }^{1}$ Universitas Teknologi Indonesia \\ ${ }^{2}$ Universitas Hindu Negeri I Gusti Bagus Sugriwa Denpasar \\ 1'tegarprabawa@ymail.com \\ 2nikomangsutriyanti@gmail.com
}

\begin{tabular}{l}
\hline Keywords: \\
\hline Youth, Ajeg Bali, \\
Globalization. \\
\hline
\end{tabular}

Abstract

In the era of globalization the development of science and technology is developing very rapidly. With the development of science and technology many foreign cultures / foreign cultures have entered Bali. Bali is one of the provinces in Indonesia which is known as the island of a thousand temples, so that a lot of Balinese culture is starting to fade. Youth plays a very important role in the success of a nation. Ajeg bali is an identity politics or movement to maintain Balinese ethnic identity that aims to restore Balinese society in the context of the experience of the teachings of Hinduism and Balinese culture (reBalinization and re-Hinduisasi). Ajeg Bali is closely related to the implementation of the Tri Hita Karana concept in social life. Where the implementation of the steady Balinese concept is expected to create harmony in Bali and preservation of traditions and culture in Bali. Youth in Bali do not consider Ajeg Bali to be a stagnant concept but rather a conscious and sustainable modernization. In practice, Balinese youth are able to defend their identity and culture from the new values and culture that globalization promotes. Cultural hegemony, has become quite painful for the people of Bali. Until then redefining the role of all elements of Balinese society, especially young people, trying to restore the meaning of Balinese culture and traditions in the daily breath of its people. Efforts to preserve the tradition above the Ajeg Bali movement lead to an increase in the strength of young Balinese so as not to fall into the conquest of global cultural hegemony. Bali's steady design even though it had to pass the commodification of the practical political interests of the authorities, but in its course this design was identified as a cultural movement. 


\begin{tabular}{l}
\hline Kata kunci: \\
\hline Pemuda, Ajeg \\
Bali, Globalisasi. \\
\hline
\end{tabular}

\section{Pendahuluan}

Pemuda senantiasa diidentikkan dengan golongan yang memiliki sifat progresif, inovatif, memiliki sensitivitas sosial-politik tinggi sekaligus peka terhadap perubahan. Rentetan historikal negeri inipun mencatat peran pemuda sebagai penggerak aksi-aksi monumental pembaruan, seperti: Pergerakan Pemuda 1908, Sumpah Pemuda 1928, Gerakan Mahasiswa 1966, hingga Reformasi 1998 yang mana mampu mendobrak dan memformat ulang ragam kungkungan lingkup kehidupan, sosial, budaya, ekonomi, politik, hukum serta bidang-bidang lainnya. Pasca reformasi 1998 banyak kalangan menilai bahwa arah pergerakan pemuda dan mahasiswa Indonesia mengalami quo vadis. Pemuda Indonesia yang sebelumnya dijuluki motor penggerak perubahan, dianggap kehilangan momentum sekaligus isu utama yang harus diangkat ke permukaan sebagai

\begin{tabular}{l} 
Abstrak \\
\hline Di era globalisasi perkembangan ilmu pengetahuan dan \\
teknologi berkembang sangat pesat. Dengan berkembangnya \\
ilmu pengetahuan dan teknologi banyak budaya luar/ budaya \\
asing yang masuk di Bali. Bali merupakan salah satu provinsi \\
yang ada di Indonesia yang terkenal dengan sebutan pulau \\
seribu pura Sehingga banyak kebudayaan Bali yang mulai \\
memudar. Pemuda memegang peranan yang sangat penting \\
dalam kesuksesan suatu Bangsa. Ajeg bali merupakan suatu \\
politik identitas atau gerakan pemertahanan identitas etnik Bali \\
yang bertujuan untuk mengembalikan masyarakat Bali dalam \\
kontek pengalaman ajaran agama Hindu dan kebudayaan Bali \\
(re-Balinisasi dan re-Hinduisasi). Ajeg Bali erat kaitanya \\
dengan implementasi konsep Tri Hita Karana dalam keidupan \\
bermasyarakat. Dimana dengan diterapkannya konsep ajeg Bali \\
diharapan dapat terwujudnya keharmonisan di Bali dan \\
pelestarian tradisi dan budaya yang ada di Bali. Pemuda di Bali \\
tidak menganggap Ajeg Bali sebagai konsep stagnan tetapi \\
lebih ke modernisasi yang sadar dan berkelanjutan. Dalam \\
praktiknya, pemuda Bali mampu mempertahankan identitas \\
dan budaya mereka dari nilai-nilai dan budaya baru yang \\
diusung oleh globalisasi. Hegemoni budaya, telah menjadi hal \\
yang cukup menyakitkan bagi kalangan masyarakat Bali. \\
Hingga kemudian pendefinisian kembali peranan seluruh \\
elemen masyarakat Bali, khususnya kaum muda, berusaha \\
untuk mengembalikan makna budaya dan tradisi Bali dalam \\
nafas keseharian masyarakatnya. Upaya penjagaan tradisi \\
diatas gerakan Ajeg Bali bermuara pada peningkatan kekuatan \\
kaum muda Bali agar tidak jatuh dalam penaklukan hegemoni \\
budaya global. Desain Ajeg Bali meski harus sempat melewati \\
komodifikasi kepentingan politik praktis penguasa, namun \\
pada perjalanannya desain ini lebih diidentikkan sebagai \\
gerakan kultural.
\end{tabular}
gerakan kultural. 
penajam arah pergerakan. Hanya saja, apabila hilangnya momentum arah perjuangan pemuda tidak hanya diakibatkan tak adanya realitas penajam isu pergerakan tapi tudingan pengaruh besar globalisasi yang melingkupi sebagian besar pemuda Indonesia.

Globalisasi telah membentuk peradaban jaman dengan menyertakan gaya hidup praktis dan pragmatis. Tidak selamanya globalisasi membawa dampak yang baik bagi negara Indonesia karena luasnya wilayah Indonesia yang terdiri dari gugusan pulau yang menyebabkan tidak terjadinya pemerataan baik terhadap akses informasi (Nasution, 2016). Bahkan globalisasi telah dijadikan isme baru di kalangan pemuda dengan menderivat paham-paham kepraktisan hidup seperti materialisme, hedonisme, hingga sifat konsumtif. Inilah yang kemudian meletakkan pemuda pada posisi yang kadang terpojokkan yaitu identik dengan golongan yang hidupnya terbalut oleh kenyamanan peradaban kapitalisme. Pada tingkatan yang lebih mikro, tulisan ini hendak melihat, apa yang sebenarnya terjadi di kalangan pemuda, khususnya pemuda Bali dalam menyikapi arah gerak globalisasi yang kian tidak menentu. Bali tidak dapat menghindari pengaruh dari kebudayaan lain (Sahriyadi, 2011). Bali sebagai kawasan cagar budaya telah lama mengalami disharmoni dimana menyertakan kuasa ketidakberdayaan selama masa pemerintahan Orde Baru. Meningkatnya jumlah penduduk yang diiringi dengan peningkatkan kebutuhan manusia dalam berbagai aspek menyebabkan terjadinya berbagai permasalahan keruangan (Atmaja, 2015). Beberapa aspek yang mengalami kondisi ketidakberdayaan tersebut digambarkan Kuntowijoyo (2000) pada beberapa aspek sebagai berikut:

Tabel 1.

Aspek yang Mengalami Kondisi "Ketidakberdayaan".

\begin{tabular}{|l|l|}
\hline Aspek & Bentuk Penyeragaman \\
\hline Ideologi & $\begin{array}{l}\text { Penataran P4 dan Jargon Persatuan dan Kesatuan sebagai harga } \\
\text { mati atas wacana federalisme. }\end{array}$ \\
\hline Birokrasi & $\begin{array}{l}\text { Pengenalan sistem birokrasi desa ala Jawa sehingga } \\
\text { melunturkan peranan eksistensi desa adat (pakraman) di Bali. }\end{array}$ \\
\hline $\begin{array}{l}\text { Bahasa dan } \\
\text { komunikasi }\end{array}$ & $\begin{array}{l}\text { yahasa Indonesia dan TVRI sebagai sarana komunikasi budaya } \\
\text { dalam pidato kenegaraan seperti konsep kepemimpinan Ing }\end{array}$ \\
& $\begin{array}{l}\text { Ngarso Sung Tulodho Tut Wuri Handayani; Sepi Ing Pamrih } \\
\text { Rame Ing Gawe, dll }\end{array}$ \\
\hline Pertanian & $\begin{array}{l}\text { De-tradisionalisasi sistem pertanian Bali (subak) akibat } \\
\text { program revolusi hijau Orde Baru (mengubah sistem lumbung } \\
\text { ke sistem pasar). }\end{array}$ \\
\hline
\end{tabular}

Sumber: Kuntowijoyo (2000): Penambahan dari Penulis 
Melalui logika pertumbuhan dan pembangunan, aspek-aspek budaya lokal saat itu dilebur dalam rangkaian sub ordinasi kebudayaan nasional yang mana oleh Atmadja (2010) nyata-nyata dianggap mengaburkan makna kebudayaan daerah yang adiluhung. Ekspresi budaya dan potensi lokal mengalami politik penyeragaman oleh pemerintah Orde Baru dengan memarginalisasi segenap elemen lokal yang ada, termasuk di kalangan pemudanya. Kondisi yang paling ekstrim ditengarai Atmadja (2010) saat mulai berpalingnya kaum muda yang mengenyam pendidikan mencukupi di wilayah desa pakraman dari sektor-sektor pertanian dan lebih banyak memilih menekuni bidang non pertanian, seperti buruh, pedagang, pegawai swasta, dan profesi lainnya.

Kondisi yang turut dibentuk oleh revolusi transportasi dan komunikasi inilah yang kemudian ditengarai makin memberikan corak heterogen bagi pengelompokkan warga masyarakat yang sebelumnya hanya disandarkan atas pemilahan kasta, strata, dan kelas sosial lainnya (Atmadja, 2010). Saat masa reformasi bergulir dan mereposisi rejim Orde Baru, pergulatan identitas asli masyarakat Bali baik dalam lingkup sosial budaya vis a vis globalisasi mulai menyeruak ke permukaan. Ragam persoalan yang melingkupi masyarakat dihadapkan pada realitas arus perubahan sosial yang pengaruhnya makin menderas hingga muncul semacam gerakan pewacanaan budaya siaga yaitu langkah pengaman pelestari tradisi Bali yang kemudian populer sebagai Ajeg Bali. Sebuah wacana besar ujud pelestarian budaya Bali yang harus dimiliki setiap generasi, termasuk kalangan muda, dalam menanggapi arah gerak perubahan global yang sedemikian cepat arusnya, termasuk perdagangan bebas, eco tourism, dan ragam tuntutan global lainnya. Hegemoni budaya, telah menjadi hal yang cukup menyakitkan masyarakat Bali. Hingga kemudian pendefinisian kembali peranan seluruh elemen masyarakat Bali, khususnya kaum muda, berusaha untuk mengembalikan makna budaya Bali dalam nafas keseharian masyarakatnya.

\section{Metode}

Metode penelitian yang digunakan dalm penelitian ini adalah kualitatif deskriptif. Teknik pengumpulan data adalah studi kepustakaan. Studi kepustakaan merupakan metode penelitian yang dapat dilakukan dengan cara menghimpun informasi yang relevan sesuai dengan judul atau topik permasalahan yang menjadi obyek penelitian yang bersumber dari buku-buku, tesis, skripsi, jurnal ilmiah, internet dan sumber-sumber yang lainnya. 


\section{Hasil dan Pembahasan}

\section{Ajeg Bali dan Penjaga Tradisi}

Ajeg Bali dicanangkan sebagai sebuah gerakan bertepatan dengan peresmian Bali TV oleh Gubernur Bali I Dewa Made Beratha, Mei 2002 yang saat itu dikomandani tokoh muda asli Bali, Satria Naradha, pemilik perusahaan media terkuat di Bali (Darma Putra: 2008). Ajeg mengandung makna tegak, kuat yang lebih diarahkan pada budaya ke-Bali-an. Dwipayana (2010) menjelaskan bahwa Ajeg Bali dapat dipahami melalui dua konsep pokok penting. Pertama, wacana Ajeg Bali, kurang lebih, dibayangkan sebagai langkah antisipatif atas kelangsungan nilai, norma, dan tatanan budaya Bali yang sedang menghadapi ancaman perapuhan, marginalisasi, bahkan penghilangan identitas ke-Balian yang sudah sekian lama kokoh, harmonis, dan lestari. Situasi ini sekaligus mensyaratkan adanya peniadaan segala bentuk ancaman yang dapat mengganggu eksistensi tegaknya budaya Bali. Pada satu sisi Ajeg Bali dipahami sebagai adat masyarakat Hindu Bali sebagai upaya untuk melestarikan nilai dan tradisi leluhurnya agar tidak hilang (Ushuluddin, 2013).

Kedua, wacana ini menyiratkan bahwa ancaman yang harus diwaspadai sebenarnya tidak berasal dari dalam, melainkan selalu datang dari luar Bali. Pada konteks ini ada penegasan atas batas tegas budaya dari Bali dan dari luar Bali. Budaya dari Bali ditransmisikan sebagai masyarakat Bali yang menjaga ketertiban sekaligus pemelihara tradisi. Sedangkan budaya dari luar Bali diartikan sebagai budaya asing, dampak globalisasi termasuk pengaruh orang-orang pendatang (kaum migran). Terkait penjaga dan pemelihara tradisi inilah, Giddens pernah mengkonsepsikan bahwa salah satu ciri tradisi adalah memiliki penjaga (guardians) yang bertugas melindungi dan menafsirkan agar budaya lebih mudah dipahami dan senantiasa kontekstual. Dalam usaha mengantisipasi tergerusnya seni budaya Bali yang adiluhung, Bali post dan Bali TV meluncurkan wacana “Ajeg Bali” yang artinya menjaga dan melestarikan identitas budaya Bali agar tidak jatuh di bawah hegemoni budaya global (Suardana, 2018). Apabila dilekatkan dengan wacana Ajeg Bali, Atmadja (2010) melukiskannya sebagai pihak-pihak yang menyertakan proses filterisasi atas pemaknaan tradisi, kepercayaan dan kebudayaan mereka sebelum akhirnya disampaikan kepada massa dengan menggunakan bahasa mereka agar mudah dipahami dan diterima.

Meski pada perjalanannya Ajeg Bali sempat dikhawatirkan memunculkan semangat etnosentrisme sebagai derivat euforia reformasi, namun menurut Putra (2008) 
gerakan ini pada akhirnya lebih dipahamkan sebagai gerakan yang mendukung sama sekali tak merusaksemangat persatuan dan kesatuan bangsa. Ia menilai Ajeg Bali hanya sebagai aktualisasi politik identitas etnik yang pada gilirannya dikomodifikasi oleh kepentingan politik praktis, utamanya saat kampanye capres cawapres 2004 dan 2009, baik oleh Susilo Bambang Yudhoyono maupun Megawati. Pada sisi lain, Ajeg Bali pun di pahami sebagai gerakan kebudayaan yang muncul ke permukaan sebagai respon orang-orang Bali yang beragama Hindu terhadap berbagai persoalan (Miharja, 2017).

Ajeg Bali memang tidak sesederhana konsep di atas, melainkan memiliki makna lebih daripada itu. Pada uraian yang lebih luas, Ajeg Bali dipahami dalam 3 tataran. Tataran individu dimaknai sebagai kemampuan manusia Bali untuk memiliki kepercayaan diri kultural yang bersifat kreatif dan tidak membatasi diri pada hal yang fisikal belaka. Tataran lingkungan kultural, dimaknakan sebagai terciptanya sebuah ruang hidup budaya Bali yang bersifat inklusif, multikultur, dan selektif terhadap pengaruh-pengaruh luar. onsep Tri hita karana adalah harmoni yang mendasari hubungan antara manusia dan Tuhan (pertimbangan), sesama manusia (pawongan) dan manusia dengan lingkungan (palemahan) (Samiyono, 2013).

Tataran proses kultural, dimaknakan sebagai interaksi manusia Bali dengan ruang hidup budaya Bali guna melahirkan produk atau penanda budaya baru melalui sebuah proses yang berdasarkan nilai moderat, non dikotomis, berbasis nilai kultural, dan kearifan lokal. Semua tataran ini kemudian disepakati bahwa ajeg Bali bukanlah sebuah konsep stagnan, melainkan upaya pembaruan terus menerus yang dilakukan secara sadar oleh manusia Bali untuk menjaga identitas ruang serta proses budayanya agar tidak jatuh di bawah penaklukan hegemoni budaya global (Naradha, Bali Post : 2001). Hanya saja pada kondisi ini, Dwipayana (2010) memberikan catatan khusus yang lebih menarik bahwa wacana ancaman penetrasi budaya luar dan dampak global bukanlah dipahami secara instan oleh masyarakat Bali, melainkan lebih dari refleksi rasa masyarakat Bali jauh hari sebelumnya, dimana mereka merasakan kesesakan sesungguhnya atas efek kekuatan-kekuatan tersebut, seperti ketika kalangan muda menghadapi masalah narkoba, pelacuran, hingga tawuran antar kelompok.

\section{Penyikapan Alternatif atas Dampak Global}

Dampak globalisasi terhadap kaum muda telah menimbulkan situasi kegelisahan sehingga masyarakat Bali perlu mengadakan suatu peng-ajeg-an (penegakan kembali) 
budaya Bali sebagai salah satu langkah solutif penanggulangan beragam masalah. Pada konteks sikap kaum muda atas invansi budaya misalnya, mereka lebih menampakkan sifat progresif, inovatif, sekaligus sensitivitas terhadap perubahan. Misalnya penyikapan atas indikasi kapitalisasi atas seni budaya Bali. Dimotori mahasiswa seni rupa kampus ISI Bali, mereka menyikapi terhadap wacana dominan seni rupa Bali yang cenderung turistik melalui pameran alternatif yang pada hakekatnya mendudukkan kembali kesenian Bali pada posisinya yang adiluhung. Aksi ini kemudian diikuti pula penyikapan atas momen tahunan Pesta Kesenian Bali (PKB) yang mereka tuding sebagai Pesta Kapitalisme Bali, karena forum ini dianggap tidak berhasil memutus lingkaran hegemoni atas seni Bali, hingga kemudian disikapi melalui aksi pameran tandingan di depan pintu masuk area kegiatan diselenggarakan, meski kemudian dapat dibubarkan aparat (Dwipayana, 2010).

Pada konteks seni budaya di sisi yang berbeda, muncul kecenderungan anakanak muda memproduksi / merilis lagu-lagu Bali bernuansa pop alternatif, rap, atau aliran-aliran progresif lainnya. Grup band lokal yang mengusung lagu-lagu berlirik Bali kian menjamur bahkan beberapa diantaranya, seperti Group Band Superman is Dead (SID) menuai sukses di pentas nasional, baik dari sisi penjualan album maupun prestasi, meski grup ini pada akhirnya bermetamorfosa untuk menampilkan lagu-lagu berbahasa Indonesia. Promosi gencar melalui media televisi lokal, Bali TV, Dewata TV maupun TVRI Stasiun Bali atas lagu-lagu Bali kontemporer saat pagi, siang, dan malam seolah mengubah perwajahan seni budaya Bali yang pada akhirnya berinteraksi dengan selera pasar global. Dwipayana (2010) menilai kecenderungan ini sebagai perlawanan dan gugatan atas wacana dominan seni budaya Bali melalui gerakan alternatif anak muda Bali yang berekspresi melalui jalur musik.

Kemunculan grup-grup band lokal sekaligus lagu lokal Bali telah menegaskan beberapa kecenderungan. Pertama, anak muda Bali telah berhasil mengawinkan keajeg-an seni budaya Bali dengan selera pasar global yang relatif lebih bisa diterima kalangan mereka. Tak hanya kemampuan memproduksi, kaum muda Bali juga telah mampu membentuk komunitas penggemar yang cukup besar atas lagu-lagu beretnik Bali yang telah mereka kreasikan sendiri, dan hal ini relatif jarang dijumpai pada wilayah lain di Indonesia. Kedua, meminjam istilah Putra (2008) kondisi menjamurnya musik kontemporer Bali telah mengubah segmen penggemar atas seni budaya Bali dari yang semula hanya sebatas kaum muda desa, bergeser ke penggemar kaum muda urban 
(perkotaan). Kemunculan grup band lokal Bali seperti Group Band Lolot dan Triple-X yang memiliki lagu-lagu Bali best seller telah memiliki penggemar fanatik di kalangan pelajar dan mahasiswa. Kondisi ini kemudian diikuti pula dengan munculnya trend pemberian penghargaan khusus bagi insan musik Bali, seperti Ajang Gita Award yang diadakan salah satu media di Bali.

\section{Kaum Muda: Antara Penyuara Ketidakberdayaan dan Ketertindasan}

Pada sisi lain, penyikapan atas situasi yang dianggap serba tidak adil dan sensitif juga ditunjukkan oleh kaum muda Bali melalui aksi reaktif namun lebih ditunjukkan dengan perilaku elegan yang masih mengedepankan aksi damai dan institusional. Hal ini bisa dijelaskan melalui beberapa fenomena, seperti sikap kaum muda Bali atas kasus pelecehan atas peringatan hari raya keagamaan melalui teknologi facebook oleh oknum pekerja pendatang yang berujung pada sanksi institusional bagi yang bersangkutan. Pelecehan Patung Ganesha sebagai simbol Dewa yang dihormati di Bali pada acara hiburan Opera Van Java yang ditayangkan salah satu stasiun televisi swasta nasional yang berujung dilayangkannya surat protes Komisi Penyiaran Independen Daerah (KPID) Bali kepada stasiun televisi bersangkutan dan disikapi lebih lanjut oleh Komisi Penyiaran di tingkat Pusat.

Pada ranah kebijakan, kaum muda di Bali juga pernah bereaksi saat hendak dirancangnya RUU Pornografi dan Pornoaksi yang dianggap mereka bisa mengancam dis-integrasi bangsa. Langkah elegan atas reaksi ini diaktualisasikan melalui pawai damai yang sifatnya lebih mengarah pada pertunjukkan seni budaya. Pada tataran isu internasional, kaum muda di Bali juga sempat bereaksi keras saat terjadi ketegangan soal perbatasan RI-Malaysia termasuk indikasi klaim atau penjarahan budaya Tari Pendet oleh Malaysia, namun semuanya masih dilakukan sebatas aksi-aksi protes unjuk rasa. Kuasa atas dominasi atas sumber daya alam maupun manusia oleh negara maupun kekuatan kapital di era reformasi ternyata masih menyisakan kegelisahan di kalangan pemuda Bali. Pengelolaan sumber dana Bandar Udara Internasional Ngurah Rai, misalnya, dianggap timpang pengaturannya oleh sebagian kalangan legislator muda yang ada di Bali. Pemerintah Pusat terkesan tidak adil terutama dalam hal sharing pengaturan keuntungan, khususnya kepada Pemerintah Propinsi Bali. Atas kondisi ini, mereka secara ekstrim menganggap otonomi daerah tidak terlalu memberikan manfaat dalam mensejahterakan masyarakat Bali. 
Di tengah-tengah sikap tegas pemuda Bali atas isu-isu persoalan yang melingkupi mereka, beberapa pengamat mengkontraskannya dengan beberapa persoalan yang sebenarnya masih mendera sebagian besar kaum muda Bali. Terkait dominasi atas sumber daya manusia, misalnya, posisi tawar kaum muda Bali terhadap sektor-sektor pekerjaan dianggap masih lemah. Beberapa kalangan pengamat menyatakan bahwa daya saing kalangan muda lokal asal Bali yang memasuki sektor-sektor pekerjaan, ternyata kondisinya masih perlu peningkatan. Seperti yang diilustrasikan Suyadnya (2010) bahwa kelompok generasi muda di Bali cenderung menganggap bahwa tanpa keterampilan yang mencukupi-pun, mereka akan optimis untuk mendapatkan tempat bekerja di sektor jasa pariwisata, khususnya jasa pariwisata perhotelan. Hal ini karena lahan yang digunakan adalah milik orang tua mereka. Atas pertimbangan meminimalisir konflik dengan masyarakat sekitar, maka pihak hotel memperkerjakan kaum muda Bali hanya pada sektor pekerjaan yang tidak berkait langsung dengan proses pengambilan kebijakan sehingga terkadang banyak merugikan posisi mereka sendiri.

Pendapat yang dikemukakan akademisi muda asal Bali tersebut sejalan dengan hasil riset yang pernah dilakukan Bawa (dalam Pitana, 2004) bahwa berdasarkan riset keunggulan SDM Bali di bidang pariwisata menunjukkan bahwa kebanyakan orang Bali, khususnya anak muda yang bekerja di sektor pariwisata, umumnya berposisi sebagai pelaksana (front liner), jarang sebagai penyelia (supervisor) ataupun manajer. Mereka memiliki keunggulan yang bersifat bawaan (personal qualities) dan kemampuan dalam bekerjasama dengan orang lain (human relation), namun kemampuan di bidang konseptual (conceptual skill) maupun aspek manajerial dan bisnis masih perlu ditingkatkan lagi. Banyak generasi muda menjadi pengangguran, sehingga menumbuhkan jiwa kewirausahaan dipercaya sebagai alternatif mengatasi keterbatasan lapangan pekerjaan dan mengurangi jumlah pengangguran (Anggraeni, 2016).

Kondisi inilah yang pada gilirannya membuka peluang masuknya orang asing non Bali maupun non Indonesia bekerja di sektor-sektor usaha yang ada di Bali, khususnya bidang industri pariwisata dengan posisi yang lebih strategis. Tenaga kerja asing dianggap lebih memiliki kepandaian dalam mengukur kemampuan mereka miliki, dibandingkan tenaga kerja kaum muda lokal dimana etos kerjanya dianggap lunak dan terlampau permisif. Pada ilustrasi ini, Sekjen APINDO Bali, Asih Wesika, mencontohkan dalam penentuan gaji atau sallary. Tenaga kerja asing dianggap lebih 
memiliki kemampuan dalam menjawab atau menentukan gaji yang diinginkannya dibandingkan tenaga kerja kaum muda lokal, baik Bali maupun warga Indonesia lainnya.

Hal inilah yang kemudian diartikan sebagian pemilik usaha pariwisata sebagai bentuk ketegasan sekaligus loyalitas kerja, sehingga mereka berani membayar lebih tinggi tenaga kerja asing di industri pariwisata yang mereka kelola dibandingkan merekrut tenaga kerja dari kaum muda lokal setempat. Generasi muda yang menjadi solusi yang berorientasi ke masa depan (Herlambang, 2015). Kemampuan dalam menghargai diri sendiri serta perlunya instrumen regulasi seperti Perda Tenaga Kerja maupun pengawasan pemerintah daerah, merupakan langkah-langkah yang dianggap solutif dalam mereduksi permasalahan ini (Dialog TVRI Bali, 2010).

Atas kondisi inilah, maka di tengah-tengah gerakan Ajeg Bali dan menghadapi arah gerak kecenderungan global, kaum muda Bali bersuara cukup lantang untuk menyikapi sekaligus mencari solusi atas problematika persoalan yang melingkupinya. Para tokoh muda Bali menilai bahwa mata rantai atas posisi tawar yang rendah dalam sektor-sektor pekerjaan hanya bisa diputus oleh kaum muda Bali sendiri, yaitu dengan cara menempuh pendidikan setinggi-tingginya (Arya Vedakarna, 2009). Dengan adanya faktor kekerabatan yang masih relatif akrab dan kuat yang didasarkan atas persamaan budaya, bagi kaum muda Bali yang sudah sukses, baik pekerjaan maupun pendidikannya, wajib membantu kaum muda Bali lainnya untuk mengentaskan dari kemiskinan, ketertinggalan maupun kebodohan. Pada satu sisi Ajeg Bali dipahami sebagai adat masyarakat Hindu Bali sebagai upaya untuk melestarikan nilai dan tradisi leluhurnya agar tidak hilang (Miharja, 2017).

\section{Kesimpulan}

Ajeg Bali dalam konteks kehidupan kaum muda di Bali tidak sebatas konsep penafsiran yang stagnan, melainkan lebih diartikan sebaga sebuah upaya pembaharuan yang dilakukan secara sadar dan kontinu oleh kaum muda sebagai integral masyarakat Bali. Tujuan yang hendak mereka capai adalah penjagaan atas identitas, ruang serta proses budaya Bali. Upaya penjagaan tradisi diatas gerakan Ajeg Bali bermuara pada peningkatan kekuatan kaum muda Bali agar tidak jatuh dalam penaklukan hegemoni budaya global. Desain Ajeg Bali meski harus sempat melewati komodifikasi kepentingan politik praktis penguasa, namun pada perjalanannya desain ini lebih diidentikkan sebagai gerakan kultural. Ujud gerakan kultural ini dianggap sangat 
penting bagi keberlangsungan hidup masyarakat dan kebudayaan Bali, yang ternyata dalam praktiknya telah memampukan kaum mudanya untuk melakukan pemertahanan atas identitas kultur mereka, meski pada ragam bentuk yang lebih dapat diterima oleh akal toleransinya terhadap globalisasi.

\section{Daftar Pustaka}

Anggraeni, D., \& Nurcaya, I. (2016). PERAN EFIKASI DIRI DALAM MEMEDIASI PENGARUH PENDIDIKAN KEWIRAUSAHAAN TERHADAP NIAT BERWIRAUSAHA. E-Jurnal Manajemen Universitas Udayana.

Atmaja, D. M. (2015). Pengelolaan Tata Ruang Berbasis Kearifan Lokal Pada Masyarakat Adat Panglipuran Kabupaten Bangli. Jurnal EKOSAINS.

Herlambang, Y. (2015). Peran Kreativitas Generasi Muda dalam Industri Kreatif Terhadap Kemajuan Bangsa. Jurnal Teknologi Informasi dan Komunikasi (Tematik).

Institut Agama Islam Negeri Jami'ah Raden Intan. Fakultas Ushuluddin., D. (2013). Majalah al-kalam : sarana kreatifitas \&amp; media informasi ilmu-ilmu agama. In KALAM.

Karuni, N. K., \& Suardana, I. W. (2018). Wacana “Ajeg Bali” Pada Seni Kerajinan Sarana Upacara Di Gianyar Bali. Mudra Jurnal Seni Budaya. https://doi.org/10.31091/mudra.v33i1.321

Miharja, D. (2017). ADAT, BUDAYA DAN AGAMA LOKAL Studi Gerakan Ajeg Bali Agama Hindu Bali. KALAM. https://doi.org/10.24042/klm.v7i1.444

Nasiruddin. (2017). Peran Keluarga, Sekolah, dan Masyarakat dalam Pendidikan Karakter Generasi Muda Bangsa. Prosiding Seminar Nasional Tahunan Fakultas Ilmu Sosial Universitas Negeri Medan Tahun 2017.

Nasution, R. D. (2016). Pengaruh Kesenjangan Digital Terhadap Pembangunan Pedesaan (Rural Development). Jurnal Penelitian Komunikasi dan Opini Publik.

Sahriyadi. (2011). Makna Budaya pada Sistem Zonasi dan Sirkulasi Rumah Tradisional di Desa Ubud Kelod, Bali. Jurnal Arsitektur Komposisi.

Samiyono, D. (2013). RESISTENSI AGAMA DAN BUDAYA MASYARAKAT. Walisongo: Jurnal Penelitian Sosial Keagamaan. https://doi.org/10.21580/ws.2013.21.2.244 